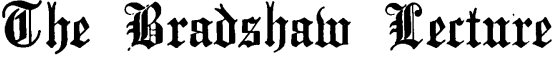

\section{DARWINISM AND MEDICINE.}

Delivered at the Royal College of Physicians, LoNdoN, oN November 2ND, 1909.

BY

JAMES ALEXANDER LINDSAY, M.A., M.D., F.R.C.P.

PROFESSOR OF MEDICINE IN THF QUEFN'S UNIVERSITY OF BELFAST ; PHYSICIAN TO THE ROYAL VICTORIA HOSPITAL, BELFAST.

Mr. President,-I trust I may with scme propriety in this year of the Darwin centenary ask you to consider with me the significance of Darwin's great discovery for medical thought and practice. The subject is large and can on this occasion be dealt with only in outline. The field which I shall ask you to traverse is a well-trodden one, but I believe its fruitfulness is not yet exhausted. Darwin's work on The Origin of Species contained, as Helmholtz said, "an essentially new creative thought," a thought, I venture to add, which is still fertile, still seminal, still full of suggestion and guidance for all whose labours lie in the field of biology.

The relation of the science and art of medicine to the higher thought of the day must always be a matter of interest and importance. Medicine is coloured by that thought; its postulates, prepossessions, and theories are modified by it; in its degree it contributes to that thought. When we get from the facts of science to the truths of science, to emphasize a pregnant distinction, our thinking is modified, stimulated, or deflected to an important extent by the intellectual atmosphere in which we live. notable instance in point is afforded by the Father of Medicine-Hippocrates. In the Homeric poems everything is miraculous. The storm, the sunshine, shipwreck, plague, blight, sickness, victory, defeat-everything is due to the direct interposition of supernatural powers. "Every event," as the late James Adam said, " is a theophany." The conception of natural law has not yet arisen. How different is the atmosphere of the works of Hippocrates! Here, amidst much that is crude and empirical, there is a genuine recognition that in the field of disease events follow a natural sequence, that effects are proportionate to causes, that order reigns, and that our business is to investigate that order. Between Homer and Hippocrates had intervened the great school of the Ionian physicists from Thales to Democritus; physical science had seen its dim and feeble dawn; the lineal succession was opened which was one day to include the names of Galileo and Copernicus, of Leibnitz and Newton, of Darwin and Wallace. The comparative failure of the successors of Galen to advance the art of medicine, and the barrenness of our art during the many hundred years during which their influence reigned supreme, were due in large measure to the false philosophy which lay at the root of the Galenic system, to the predominance of metaphysical theory over observation and experiment. The rapid advance of medical science in modern times has coincided with the progress of physical and biological science in general, in part because science furnishes medicine with instruments of precision and methods of research, but perhaps even more because it creates the atmosphere in which medicine can flourish and develop. The reaction of one branch of science upon another branch at the present day is both potent and prompt.

I need not inform you that the conception of evolution existed long before Darwin, and goes back to the very. dawn of science. It is said to occur in the sacred books of the Vedas. It was the central thought of the philosophy of Heraclitus. It is found in the works of Aristotle, and we can trace it through a long succession of thinkers, including Bacon, Descartes, Leibnitz, Hume, Kant, Goethe, Buffon, Geoffrey St. Hilaire, Erasmus Darwin, and Lamarck. It is interesting to note that one of the most notable precursors of Darwin was a member of our own profession, Dr. James Cowles Prichard of Bristol. . Writing in the year 1826, Prichard clearly recognized the existence of organic evolution. He fully apprehended that domesticated races of animals and plants have been produced by selection by man, and not by the inflaence of environment; he recognized the operation of natural selection, though he misinterpreted its range and importance; and, most curious of all, he recognized the difference between acquired and congenital characters, and argued for the transmissibility of the latter and the non-transmissibility of the former-a view reached independently half a century later by Weismann, and now usually associated with his name. Darwin did not discover Evolution. He discovered its leading law, and by a long series of observations, experiments, and reflections, unparalleled in the history of science, converted the brilliant guesses of earlier inquirers into an assured truth and an established principle.

We claim for Darwin (Alfred Russel Wallace says) that he is the Newton of natural history, and that just as surely as that the discovery and demonstration by Newton of the law of gravitation established order in place of chaos and laid a sure foundation for all future study of the starry heavens, so surely has Darwin, by his discovery of the law of Natural Selection and his demonstration of the great principle of the preservation of useful variations in the struggle for life, not only thrown a flood of light on the process of development of the whole organic world, but also established a firm foundation for all organic world, but also
future study of Nature.

The conception that the organic world is the scene of an incessant struggle, of a keen vital competition, in which the fittest survive-that is, the fittest for their environmen in the capacity to obtain food, resist their enemies, and propagate their kind-while the unfit perish, has been recognized as the fundamental law of life, and the demonstration of this principle we owe to Darwin and to Wallace. As Weismann says, this principle "has become the basis of the science of life"; it "has conquered the world," and has become so inwrought in the texture of our thought that it is now practically impossible to think of any biological problem except in terms of evolution. That any of the fundamental features of the Darwinian doctrine have been subverted by fifty years of inquiry and controversy is not, to my mind, a tenable proposition. It is true that some of the subordinate features of that doctrine remain open questions: how far, for example, use and disuse have operated in producing organic changes; what weight is to be assigned to the influence of the environment-a point upon which careful readers of the works of Darwin will see that his mind wavered from time to time-what is the precise significance and area of operation of sexual selection ; whether acquired characters are inherited or not; how far the Mutationism of De Vries and others operates instead of slow and almost imperceptible change. On these points finality has not yet been attained, but their solution-whatever it may be-will not invalidate the Darwinian doctrine. The general tendency of inquiry since Darwin's time has been, upon the whole, to strengthen the claim of Natural selection to be regarded as the great law of organic life, to show how wide its range, how subtle its operations, and to minimize the importance of other factors. To take an example -at first sight nothing can be more obvious than to attribute to the effect of disuse the loss of sight by fish, crabs, and rats inhabiting the dark caves of Kentucky and Carniola. But another view is at least tenable. When, owing to the absence of light, the faculty of sight ceased to be of utility to these creatures, natural selection, of which the function is to keep every organ which is of use to any creature up to the mark, ceased to operate, and it is a fundamental law that any organ withdrawn from the conservative action of natural selection tends to degenerate. The controversy especially associated with the name of Weismann, whether acquired characters are inherited or not, is one of vast and far-reaching importance for practitioners of medicine. Weismann, as you are aware, holds that in all organisms there are two kinds of plasm, the somatic and the germinal; that the permanent germ plasm passes unchanged through a series of generations and is not affected, or but little affected, by environmental influences, which affect the somatic plasm; that modifications produced upon the somatic plasm by the environ. ment and by use or disuse are practically limited to the individual and not transmitted to the offspring, and that hence no characters except those predetermined in the germ are available for evolution. This question is too 
large to be discussed at any length on this occasion. Medical opinion has been to a large extent opposed to the views of Weismann, but it must be admitted that he has succeeded in throwing great doubt on the transmissibility of acquired characters, a doctrine which Darwin assumed as too obvious to require demonstration. Most of the supposed cases of such transmission are apparent rather than real. Syphilis seems a crucial case in point, hereditary syphilis being one of the most familiar of phenomena. But it is now practically certain that this is not a case of inheritance at all, in the strict sense of the term, the true explanation of the facts being an antenatal infection of the ovum, usually from the maternal side. Whether tuberculosis is ever directly conveyed from parent to child is still doubtful, but if such transmission were proved, the most probable explanation would be the direct inoculation of the embryo and not inheritance. To disprove Weismann's doctrine, we should require to show that mutilations, or the results of training, exercise, or education, or acquired diseases, reappeared in the offspring as the result of heredity. This has not been hitherto conclusively shown. The problem is one which has great interest for us, and medical observers might contribute to its solution. May I suggest a case in point, where evidence from the side of medicine might be available? In a certain proportion of cases neurasthenia is brought on by overstudy, anxiety, overwork, want of sleep, or excess of some kind, in persons where no congenital tendency to nervous disease can be suspected. Is such neurasthenia transmitted either as neurasthenia or some allied condition? The question is worthy of attention, and an answer ought to be possible.

Darwin as a scientific worker presents us with a model for all time, and worthy of admiration and imitation. "My success as a man of science, whatever this may have amounted to," he tells us, "has been determined by complex and diversified mental qualities and conditions. Of these the most important have been a love of science, unbounded patience in long reflecting over any subject, industry in observing and collecting facts, and a fair share of invention and common sense." In another place be says, " Whatever I have done in science bas solely been by long pondering, patience, and industry." This is altogether too modest an estimate. Darwin, in point of fact, possessed in a supreme degree two faculties rarely present in perfection in the same individual-namely, immense industry and accuracy in the accumulation of facts, and a daring originality of speculation, coupled with much caution in drawing any final conclusions. He had the power of keeping any subject more or less before him for a great many years. He was an indomitable theorizer, and held that "without speculation there is no good and original observation." Again, he says, "I cannot resist forming a hypothesis upon every subject." The essential fairness and integrity of his mind is shown by the following passage :

I had also during many years followed a golden rule, namely, that whenever a published fact, a new observation or thought came across me which was opposed to my general results, to make a memorandum of it without fail and at once, for I have found by experience that such facts and thoughts were far more apt to escape from the memory than favourable ones.

May I suggest that in much of the above there is a wholesome lesson for ourselves? That we should be diligent, patient, and thorough in the collection of facts goes without saying. That we should keep those facts for long periods, even for years, before our minds before drawing, still less publishing, our conclusions will seem a hard saying to the contributors to periodical medical literature. Perhaps, indeed, such a rule is a counsel of perfection, hardly possible to the average man. But I would ask you to note the high place assigned by Darwin to theorizing and speculation in scientific work. This may seem a dangerous doctrine, but I am convinced that it is a sound one. Medical science is to-day overweighted by the accumulation of a vast array of more or less crude and isolated facts. What we need is the illuminating generalization, the daring hypothesis, to co-ordinate facts hitherto out of relation with each other, to give perchance to science a new organon, to light the way to fresh fields of inquiry and discovery. It is the presence of this element of underlying theory or law which lends so much attractiveness to the work of Pasteur and Lister, of
Koch and Metchnikoff, of Ehrlich and Wright. The bold hypothesis lights up the dark ways of Nature, illumines the road already traversed, sheds light on the pathway which lies ahead.

Before proceeding, after the foregoing more or less preliminary observations, to apply the principles of Darwinism to man in health and in disease, I may be permitted to remind you of the fundamental laws of growth, which must guide us in our inquiries. These laws might be stated as follows:

(a) The Law of the Perpetuation of Species or of the Unity of Type.

(b) The Law of Variation.

(c) The Law of Reversion.

(d) The Law of A tavism.

(e) The Law of Correlation, whereby when one organ varies other organs tend to vary also.

$(f)$ The Law of Compensation or Economy, whereby in increase of growth of one organ is accompanied by diminution in growth of another organ.

(g) The Law of Sexual Selection.

We might summarize the foregoing laws as follows: The general tendency in all living organisms is that the child shall resemble the parent in specific characters-that is, that the unity of type shall be preserved. But variation from type is always present to a greater or less degree. Darwin thought that variation was largely due to changed conditions of life. Weismann believes that sexual reproduction is the chief cause of variation in the higher animals, including man, and Wallace shares this view. Variation is accompanied by a tendency to revert to type. Hence, notable departures from type tend to die out, but to this law there are many curious exceptions-for example, the Ancon sheep and the numerous "sports" amongst plants which have given rise to permanent new varieties. Atavism is the law whereby the child sometimes resembles the grandparent or the great-grandparent more than the parent. It may be regarded as a special case of reversion. By the law of correlation we mean that principle whereby when one organ varies another organ varies, the two organs not always being ralated in function. Thus, white cats with blue eyes are always deaf. In certain breeds of cattle colour and susceptibility to the attacks of flies are corre. lated. By the law of compensation or economy we mean that principle whereby nutriment required by the overgrowth of one organ is wilhdrawn from another organ. I is probably in consequence of this law that the highly. specialized reactions of the nervous system developed in an advanced stage of civilization are accompanied by a decline in the birth.rate. Finally, sexual selection is undoubtedly a factor, although much uncertainty exists as to its extent of range and importance. The comparative absence of hair from the human body, especially in the female sex, has been attributed with much probability to sexual selection.

\section{Darwinism and Normal Homan Structure and} Function,

Man is a member of the animal series, and it is reason. able to expect that the ordinary laws of evolution would be exemplified in his structure and in his functions. This we find to be the case. The body of man is built upon the same lines-bone for bone, muscle for muscle, artery for artery-as that of the higher apes. The comparatively few distinguishing features of the human organism have relation to three points-namely, the assumption by man of the erect posture, his acquisition of special manual dexterities, and his higher cerebration. The foot, the hand, and the fore-brain are almost the only points with regard to which the human body differs essentially from that of the quadrumana. Evolution accounts easily and adequately for these differences. Let us look at a few points less obvious than these. Why out of every score of human beings are about nineteen right.handed and one left-handed? On any creationist hypothesis this question admits of no plausible answer, but evolution suggests a highly probable explanation of the mystery. We may fairly assume that as man developed, and his functions became more specialized, it was necessary that certain parts of his structure should acquire special dexterities, and that it was by the law of economy that these dexterities were concentrated upon one limb instead of being shared by both. Hence were developed the special manipulations of the right hand. But the law of variation 
above mentioned would suggest that in a matter of this kind evolution would not act with undeviating uniformity, but would admit of certain departures from type. And so we find, as we might have anticipated, that about one person in twenty is left-handed. That the special dexterities of the right hand are not innate and predetermined but the result of development is shown by the fact that the left hand contains potentially the same aptitudes as the right, and these aptitudes can be successfully developed when the right hand is lost as the result of accident or disease.

Why are the speech centres in right-handed people located on the left side of the cerebrum? The most probable explanation-first suggested, I believe, by Moxon-is that by the same law of economy it was in the interest of the developing organism that the centres presiding over the mechanisms of speech-the precise significance and mode of operation of these centres is not here in question - should be located in one, rather than in both, hemispheres. It is entirely in accord with this theory that the right side of the cerebrum should contain potential speech centres, and that these should be capable of successful and adequate development when the centres on the left side are destroyed by disease. It is also quite in line with evolutionary doctrine that the same side of the cerebrum should preside over the fine manipulations of the right hand and the complicated motor mechanisms of speech.

Why are the teeth so often crowded together in the human jaws that the removal of some of them is often a necessity in early life? Evolution affords the probable clue. There are good grounds for concluding that the human jaws are undergoing a progressive diminution in size. This diminution should be accompanied by a corre sponding diminution either in the size or number of the teeth, but it is quite in accord with experience in other departments that the two processes should not proceed pari passu. Apparently the diminution in the size of the jaws has outrun the diminution in the size or number of the teeth, and hence the overcrowded state of the jaws which we know to be common. This explanation is adequate and probable, although it might be argued that the teeth are of less utility to man now than in earlier ages, and are hence partially removed from the operation of natural selection.

Many of those whom I address must sometimes have reflected over the curious and apparently clumsy arrangement whereby our food and drink, before entering the gallet, have to pass over the entrance to the air passages, involving a slight but appreciable risk of foreign matters finding their way into the lungs-a risk slight in health but sometimes serious in disease. The explanation suggested by evolutionary law is that the lungs have been developed from the swim-bladder of an unknown progenitor, and that an organ originally adapted for flotation has been developed as an organ of respiration. The relation of the swim-bladder to the gullet would not have involved the same risks as the relation of the gullet to the air passages. If we accept the alternative view of the origin of the lungs-namely, that they have been developed from a pair of gill clefts-the same explanation will apply.

Why is the septum between the auricles of the heart so imperfect that the passage of blood from one chamber to the other is only just obviated in the normal individual, while patency of the foramen ovale is one of the commonest of malformations? May it not be that we have here an example of imperfect and not yet completed development May we not expect that the present valvular arrangement for preventing the flow of blood from one auricle to another will in the course of time, under the influence of natural selection, be converted into a permanent and complete septum?

Darwinism and Rudimentary Organs.

Perhaps on no. subject has evolution thrown a more welcome or a more satisfying light than upon the signifi. cance of rudimentary organs. At first sight, nothing can be more puzzling than that there should be in the human body certain organs which are functionally useless to the individual. Of such organs we have the following:

(a) The panniculus carnosus, corresponding to the muscles which move the skin in the lower animals. There are some 4 persons who possess the power of moving at will the skin of the scalp and other parts, and I believe the music halls once possessed an artist who earned an honest livelihood by exhibitions of his power to throw plates and other articles from his head by contractions of the scalp muscles.

(b) The ear muscles, functionally inactive in most individuals but in exceptional cases capable of causing movements of the pinna, suggestive of the great importance of the movements of that organ to the lower animals.

(c) The animal ear-point, a projection upon the outer fold of the ear, present in some persons and corresponding in position to the pointed ear of many animals.

(d) The rudimentary nictitating membrane or plica semilunaris.

(e) The vermiform appendix, functionless in man, but of grest importance in some of the vegetable feeders amongst the lower animals.

(f) The foramen supracondyloidean.

In addition to the above there are certain organs which seem in process of becoming rudimentary and functionless. Cutaneous hairiness is no longer of service to man, and will probably disappear under the operation of natural selection, perhaps assisted by sexual selection. The third molar or so-called wisdom teeth, are probably becoming functionless. They pierce the gums late, or in some cases not at all, and they are prone to early decay. It seems probable that the sense of smell, no longer of much practical importance to civilized man, and hence removed from the action of natural selection, is becoming rudimentary. The human toes, with the exception of the great toe, which is of service in maintaining the upright posture, being no longer organs of prehension and almost functionless, are undergoing elimination.

Rudimentary organs present no difficulty to the evolutionist. They are simply belated survivals of organs once functionally important to the race, but now on their way to extinction and disappearance. No longer under the conserving influence of natural selection, they are very prone to vary and to become the seat of disease. Wo see this law well exemplified in the case of the vermiform appendix, which is both highly variable in structare, and very subject to disease.

It has been suggested that the many feet of the human intestine are simply survivals from a herbivorous progenitor and of no service to a mixed feeder like man. It has even been proposed that the aid of surgery should be invoked to curtail some of its superfluous folds, which; it is argued, are not only useless, but actually a source of danger. On such a delicate subject I prefer to express no opinion. Modern surgery does not need to be stimulated to fresh fields of enterprise, least of all by a physician.

The bearing of evolution upon physiological processes opens up a wide field for reflection and speculation. We are so apt to regard these processes as fixed and final, while in reality we should regurd them as fluid; variable, undergoing a process of adaptation rather than as completely adapted, imperfect, but under the influence of natural selection tending towards perfection, or in some cases, perhaps, exhibiting traces of reversion. The phe: nomena of digestion, for example, will appeal to our intellect and imagination very differently according as we regard them as ultimate and final facts, or as part of an evolutionary process. Man has gone through many phases in the matter of his food, and it is likely that he has still in this department a journey to go. Perhaps it might savour of irony to suggest that vegetarianism is a case of reversion to the habits of remote herbivorous ancestors, but the idea is one worth thinking over. When we are urged to lessen our consumption of butcher's meat and rely more upon nuts and salads, the question arises how far carnivorous habits are for man in the natural line of development, how far he should regard himself as essen: tially a mixed feeder, how far reversion to the dietetic habits of earlier ages would be a gain or a retrogression. The really illuminating thought amongst these somewhat difficult problems is that the habits of man are not predetermined and final but the result of countless generations of evolution, that they are neither wholly good nor wholly bad; that, on the one hand, they are worthy of respect as having stood the test of an immense experience, while, on the other hand, they are almost certainly destined to important modifications in the future. In this case however, as always, natural selection and adaptation to the environment will be the guiding principles to which man in his arduous march through time will be compelled to conform. 
Darwinism and Disease.

What light can evolution throw upon disease, upon its origin and course, upon the response of the organism to its assault, upon immunity and proclivity, upon the principles and results of treatment? On all these heads something might be said, but the issues thus raised are too far reacbing to be adequately dealt with on the present occasion.

An inquiry into the origin of disease in the biological sense may well seem futile. How the tirst bacillus of tubercle or the first plasmodium of malaria came into being may be plausibly regarded as a problem as mysterious and as futile as the orivin of matter or the origin of life, questions which Darwin always refused to discuss. "It is mere rubbisb," he says in one of his letters, "thinking at present of the origin of life; one might as well think of the origin of matter." Yet the origin of life has provoked many epeculations, incon. clusive, but not absolutely vain and sterile. The origin of a morbific micro-organism can be only dimly surmised, but evolution may help us to understand how such organisms have acquired their potency for mischief. In some casesfor example, tuberculosis - there is reason to believe that civilization and the habits of civilized man have had much to do in conferring toxicity upon an organism comparatively innocuous under more primitive conditions of existence. Many facts of bacteriology suggest to us that organisms such as the pathogenic bacteria owe a large part of their virulence not so much, as it were, to their inherent properties, as to certain conditions of growth which are only very partially known to us. If this view be sound, it will follow as an obvious corollary that tuberculosis is to be suppressed, not by destruction of the bacillus, but simply by depriving it of the conditions necessary for its growth and development.

Evolution may throw some light upon the different effects which the same etiological factors are known to cause in different individuals. Over-indulgence in eating and drinking produces in one individual gout, in another cirrhosis of the liver, in a third renal disease, in a fourth arterio-sclerosis, and so on. How are we to account for the different responses to the same stimulus? We have to assume some congenital peculiarity in the individual, the result of factors which may stretch back to a remote past, and which have been developed in accord with evolutionary laws. A similar train of reflection is suggested by the facts of immunity, a subject upon which so much brilliant work has been done in recent years. The precise mechanism of immunity, the action of phagocytes, alexins, or other protective agencies, need not be here dwelt upon. The effects of food, temperature, fatigue, of previous diseases, of protective inoculation whereby the specific protective substances have to be formed in the body itself, and of immunization by transference of protective substances previously formed in antitoxic serum, are well known to you. What seems clear is that when full account has been taken of all secondary causes of immunity,. we are thrown back upon a factor which we may vaguely describe 2.8 "constitutional," or "congenital," or as a personal peculiarity or idiosyncrasy. Why does one individual fall a ready prey to scarlatina or diphtheria while another resists repeated exposure to contayion? It is of great interest to learn that certain protective agencies are at work, which can be, to a certain extent, recognized. But it is clear that the recognition of such agencies only pushes the problem farther back, and does not finally solve it. That the predisposition to contract infective disease, or to resist infection, runs strongly in.families is a matter of daily observation. Some people, as the saying is, "catch everything that is going," others escape though equally exposed to infection, and these peculiarities are found to characterize certain stocks and strains. Again, some persons on being infected quickly develop all the usual consequences of infection, while others develop them slowly, or imperfectly, or even not at all. We are familiar with the fact that the bacillus of diphtheria may be present in the fauces of healthy individuals who have been in close contact with stfferers from the disease, and no further development occur. It is probable that most of us at some time or other have received the bacillus of typhoid fever into our systems, in most cases without injurious result. I may even suggest to you that some persons have tubercle bacilli in their sputum, and seem very little, if at all, the worse for their presence. These facts might he multiplied indefinitely, and they all point in one direction, namely, that when all the secondary agencies of immunity bave been unveiled-and the inquiry into them is one of extraordinary interest and importance-we shall still be left with some unexplained factor, some congenital or hereditary element which bas arisen in accord with evolutionary law. We have facts which suggest to us that civilized nations are undergoing a process of gradual immunization to infective disease. When measles was first introduced into the Faroë Islands and the Fiji Islands there was an enormous mortality, amounting in some cases to one quarter of the entire population, while subsequent epidemics have shown a much lessened virulence. In accounting for such facts there seem to be two possible theories: (1) That certain inhabitants of these islands possessed a special susceptibility to the toxin of measles; or (2) that the population as a whole in some way developed an acquired immunity, of course to an incomplete extent, against the disease. The .extraordinary virulence of Asiatic cholera when it first penetrated from its original home in Bengal to Europe and America is a phenomenon of the same category, while its declining severity in subsequent invasions, which is so often attributed solely to improved hygiene and greater caution regarding food and water, may really be due in part to the operation of an evolutionary law. Why are negroes so resistant to yellow fever, so susceptible to tuberculosis and small-pox? May it not be that the explanation is evolutionary, that the negro has been longer in contact with the first. mentioned disease than with the remaining two, and has hence acquired a certain degree of immunity against it ? Why are Anglo-Saxons in India so much more susceptible to typhoid fever than the native inhabitants? Is it because thelatter, inhabiting a country where hygienic laws are so little recognized, have developed a considerable degree of immunity? Or is it, as some affirm, that a large proportion of the native inhabitants suffer from mild attacks of typhoid fever in youth, and hence are protected during the rest of their lives? Tuberculosis is rapidly declining amongst nearly all civilized nations. Is this exclusively the result of improved hygiene, a higher range of comfort, better houses, better food, or is it in part the effect of a gradually developing immunity? Further, it may be asked, Are the two views really incompatible one with the other? How far is an acquired immnnity due to improved methods of living? Again, we may ask, Is the growing sobriety of civilized nations the result of a gradually developing immunity against the injurious effects of alcohol? Are the drunkard and the intemperate undergoing a process of slow but sure elimination?

My object is not to affirm any dogmatic opinion on these important issues, but to suggest to you that in our thinking on these matters we must take a wide and philosophic view; we must recognize that in disease great secular processes, as well as more concrete causal factors, come into view. The present generation of medical workers and observers is somewhat impatient of those conceptions of "diathesis" and "temperament" which meant so much to our predecessors. We are disposed to think that these ideas lack definiteness and concreteness, that they are too vague to be of any real utility. Yet a study of evolution in its bearing upon disease may suggest to us that these terms, vague though they are, adumbrate a great truth-namely, that in proclivity to infection and response to disease nothing is so potent as what we vaguely call "constitution," "temperament," " hereditary tendency," and the like. We have been intent upon the "search for the microbe," a search which has already yielded brilliant results, and, it is needless to say, must be continued. But the response of the organism is an element at least as important as the presence of the germ. In the future it may turn out that we shall be compelled to devote less attention to the seed, more attention to the soil.

Evolution is capable of throwing a flood of light upon many of the most familiar phenomena of disease. We are apt to accept these phenomena as ultimate facts, as the effects of a toxaemia or of some other obvious causal factor. But it is possible to push the analysis a little deeper, to trace the true inwardness of morbid phe. nomena a little farther back. Let us ask the question, 
How does it happen that in an ordinary case of hemiplegia the arm suffers more than the leg or the face; and in the arm, why is it the finer movements of the fingers and hands which suffer more than the coarser movements of the elbow and shoulder? It is easy to answer that the reason is anatomical and relates to the seat of injury and the distribution of fibres in the internal capsule, but this explanation needs itself to be explained. Here, again, we may, without extravagance, invoke evolutionary law to help us. The fine manipulations of the hand and fingers are in all probability the last to be acquired by the developing organism; they are the least stable acquisitions of nervous tissue; they are the first to suffer under the shock of disease. The nervous system, as it were, most easily forgets the lesson most recently learnt, just as the old man forgets the events of yesterday while he remembers those of fifty years ago. Aptitudes recently acquired in the genetic series are less ingrained, as it were, in the nervous system than those which go back to an earlier stage of development. Dr. Hughlings Jackson long ago pointed out the order of the dissolution of function in the brain when under the influence of alcohol. The first to go are the highest faculties-judgement, memory, taste. In the next stage speech becomes affected ; it becomes thick and indistinct. Next the emotions are involved; the individual becomes hilarious, maudlin, or quarrelsome. Last of all the centres of organic life-respiration, circulation, deglutition-are affected, and death may ensue. Now, this order of events is not fortuitous. The nervous functions, under the influence of a narcotic poison, undergo dissolution in a definite order, the order of development, which corresponds to the order of complexity and specialization. I is probable that this law will be found to have a somewhat wide application in the field of disease. General Paralysis of the Insane is a good case in point, the elements of character and judgement usually suffering before those of voluntary movement.

That the laws of evolution and the influence of heredity throw light on the response of the organism to disease will, I think, be generally admitted. We are not wrong in attaching weight in prognosis to any known family tendency in connexion with any given case of disease. It helps us in forming some estimate of that subtle and in tangible, but most potent, element, what we vaguely call "the resisting power of the individual." In many cases of disease we give the first place in prognosis to what is termed "the observed tendency of the individual case." This is not a truism, though it may sound like one. Let me take an illustration. A patient presents himself with the signs and symptoms of slight incipient tuberculous infiltration of one apex, and the question of prognosis arises. We know that the disease may either undergo early and complete arrest, or develop to a certain extent and then undergo regressive fibrotic change, or progress to softening and excavation, or become rapidly disseminated throughout the pulmonary area. It is quite out of our power to predict with certainty which of these events will happen but, in attempting any forecast, nothing is more helpful than attention to family history on the one hand, and, on the other hand, to "the observed tendency of the individual case," which time alone can reveal. We are dealing with the power of resistance which the individual can offer to the action of the tuberculous toxins, and that power is partand parcel of the individual's heredity and "constitution "-it is developmental and evolutionary.

It has been debated whether there is any such force as a Vis Medicatrix Naturae. Many have regarded the existence of this force as obviously written on the face of Nature, while others have denied even its existence. Can evolution throw any light upon this question? Nothing can be more certain than that Nature tends to revert to the normal. In another connexion Francis Galton calls this "the law of regression towards mediocrity" ; in other words, the tendency is for the abnormal to disappear, and for the unity of type to be preserved. Darwin thought that this law had a wide application, and was even in. clined to believe that tall men often married short women, and that clever men often married silly women-Nature's unconscious protest against the abnormal and unconscious striving to preserve the unity of type. If such a law exists, we might argue without paradox that disease is the abnormal, and that, on the broad grounds of evolutionary law, we might expect the tendency to be to eliminate the abnormal and to return to the normal. That tendency may, of course, be too weak successfully to resist the forces in opposition to it.

\section{Darwinisy and Race Problems.}

Let us now turn to a field where by general consent the influence of evolution has been potent. The "survival of the fittest "- a term first suggested by Herbert Spencerand its correlative, the "elimination of the unfit," have been generally accepted as expressions which succinctly sum up the effects of the operation of natural selection. It is important to remember that "fittest." does not mean best, either physically or ethically. It simply means fittest for the conditions of existence in any given case, most fully adapted to the environment, best able to succeed in the struggle for existence. Evolution does not necessarily involve progress, though the general law is pro gression from the lower to the higber, from the less to the more specialized. "Everything depends upon adapta. tion," says Weismann, and Höffding reminds us that "adaptation and progress are not the same." Degenera. tion is as truly evolutionary as progress, the upward and the downward movement being both the result of adaptation. Further, evolution does not postulate that organs and organisms are perfectly adapted to their present needs and conditions. They may be in process of becoming perfectly adapted. Natural selection, Darwin reminds us, tends only to make each organic being as perfect as, or slightly more perfect than, the other inbabitants of the same area with which it comes into competition. When competition ceases, natural selection ceases. "Natural selection," says Hugo de Vries, "acts as a sieve; it does not single out the best variations, but it simply destroys the larger number of those which are, from some cause or other, unfit for their present environment. In this way it keeps the strains up to the required standard, and in special circumstances may even improve them." The conditions of racial efficiency as defined by the laws of evolution would seem to be the following :

(a) The race must become progressively adapted to its environment, and by environment we mean climate, food supply, and competition in the struggle for existence.

(b) There must be competition and struggle, leading to elimination of the untit, otherwise degeneration will take place.

(c) There must not be too much inbreeding, and each strain must be from time to time crossed by another and allied strain.

To this last law there are, however, some curious exceptions. When we compare man with the lower animals in these regards we are at once struck with some obvious points of contrast. Man is not subject to the unrestrained operation of natural selection. He wears clothes and builds houses to protect himself from the storm and cold. $\mathrm{He}$ brings food from farthest East or remotest West to make up for the deficiencies of the home supply, and be lays up stores against the day of famine. He protects the reproductive function by law and custom. He restrains the warlike instinct and keeps it within bounds. He prevents or cures disease, makęs life possible for the feeble, the ailing, and the malformed, and even gives them the opportunity of propagating their kind. He cherishes the aged, and enables them to prolong their days. By some of his laws-for example, the law of primogeniture-he sets the principle of natural selection at defiance. In these and other ways the ordinary usages of civilized society run counter to the operation of natural law, and it becomes an anxious question whether civilization in so doing does or does not contain the seeds of its own dissolution. Rousseau and his school believed that civilization involved degeneration. Evolution was not within the purview of their thought, but we cannot evade the issue-Does evolution strengthen the contention which these thinkers reached by a process of intuition, whether true or false? We hear much to-day of the degeneracy of the nation, and the existepce of such degeneracy is assumed by many writers. The question is, however, one of extreme com. plexity. It is almost impossible to obtain the data for a just comparison as regards physical fitness between the present and preceding ages. On the one hand, the ratio of defectives-including deaf and dumb, lunatics, epileptics, paralytics, infirm, etc. - is said 
to have increased from 5.4 per 100 over fifteen Jears in 1874 to 11.6 in 1896 . On the other hand, there are some encouraging facts. The average duration of life is increasing. Some of the worst scourges of the human race-tuberculosis, typhoid fever, malaria-are abating their severity; the sick-rate of nur benefit societies is declining. But these facts are not irreconcilable with the possibility of physical degeneracy. In the absence of conclusive data on this crucial question, we may ask whether any light is obtainable from the study of evolutionary law. Are there any analogies from plant or animal which may contain suggestion for us? Domestication amongst plants and animals is the analogne of civilization amongst men. The effects of domestication are, however, exceedingly complex. In some animals-for example, the bear family and carnivorous birds-domestication leads to sterility; in others -for example, sheep, pigs, and barn-door fowl-domestication seems to increase fertility. Many flowers become double under cultivation and continue fertile, while other double flowers lose their power of producing seed. Some highly-bred animals develop a marked delicacy of constitution and become very liable to disease. In some plants an artificial increase in the richness of the soil tends to the production of wood fibre rather than of flower and seed. On the whole, the above facts do not help us. The main question remains, Does civilization, by preserving the unfit and pre venting their ruthless elimination which takes place in a state of Nature, imperil the physical integrity of the race? Our marriage customs-for example, the not uncommon conjunction of youth and beauty with age and wealth, the transmission of enfeebled constitutions and sometimes of actual disease from parent to child-can such things be tolerated without grave risk to the physical welfare of humanity? Is the medical profession free from serious responsibility when it preserves those whom Nature has plainly marked out for elimination, and even enables them to transmit their unfitness to their descendants? These are not extravagant or sentimental questions They are, on the contrary, highly practical questions, and if we so often keep them out of sight, I suspect it is from an uneasy subconsciousness that they involve painful and paralysing issues.

That civilization runs counter to natural selection is, I think, evident. It interposes artificial barriers to the free play of those forces which in a state of Nature give the victory, both as regards personal existence and opportunity for perpetuating the species, to the strong, the brave, the fit. But it is not to be assumed without argument that civilization is dependent upon natural selection. According to Lloyd Morgan, "Natural selec. tion has long ceased to be the dominant factor in human progress." The same view is propounded by J. B. Bury in the following passage: "It may be said that, so far as concerns the actions and movements of men who are the subject of recorded history, physical environment has ceised to act mechanically, and in order to affect their actions must affect their wills first, and that this psychical character of the casual relations substantially alters the problem.... Most thinkers now agree that the chief clues to the growth of civilization must be sought in the psychological sphere. Imitation, for instance, is a prin. ciple which is probably more significant for the explanation of human development than natural selection." That is the view of a historian, and it must be admitted that it contains a great deal of truth, though not the whole truth. Mankind is more dependent for its progress upon the brain of a Pasteur or a Lister, a Kelvin or a Marconi, than upon the muscles of many cricketers, footballers, or oarsmen. The puny, sickly, or deformed child, which, in a state of nature, would be promptly eliminated, may possess the brain of a great discoverer, poet, or statesman. Yet physical soundness can never be ignored or deemed of small significance. If physical degeneration is going on in our midst-and who can deny the fact, however much we may differ as to the extent of the fact?-we may feel sure that it is due to some species of non-adaptation to the environment. We are inclined to attribute such degeneration as exists mainly to unwholesome surroundings, bad housing, bad air, bad food, insufficient exercise, unsuitable clothing. "These factors have weight-perhaps much weight-but a study of the phenomena of evolution may well make us doubt whether they are really the heart of the problem; whether, after all, the main thing is not that we are to a more or less extent breeding from the wrong stock. Few men have had less reason than Darwin to retract any opinion once definitely formulated, few have been from first to last more consistent in their views, but it is clear that Darwin wavered much and wavered often as regards the weight to be assigned to external conditions-climate, food, occupation - as factors of evolution. He was at one time inclined to attribute very little weight to such conditions in comparison with natural selection, later in life he was disposed to assign greater importance to them. Some of his followers have regarded these factors as insignifi. cant. The point is one on which I shall not attempt to pronounce, but I shall content myself with the contention that race degeneracy, where it exists, is not to be satisfactorily explained by the operation of temporary and transitory causes, but must be sought in the most profound laws of growth and survival. Let us look at another racial problem in the light of evolutionary law-namely, infant mortality - which we are all agreed is excessive. Is infant mortality due simply to bad hygiene, unsuitable food, careless mothering, or is it in any sense the analogue of the terrific waste which we know to go on in Nature? Stand under one of our forest trees and watch the clouds of pollen which fall around. How many of these granules ever reach an ovule? In a well-known passage Tennyson tells us of the sad misgivings which the spectacle of the portentous waste in Nature excited in his breast:

Are God and Nature then at strife,

That Nature lends such evil dreams?

So careful of the type she seems,

So careless of the single life;

That I, considering everywhere

Her secret meaning in her deeds,

And finding that of fifty seeds

She often brings but one to bear,

I falter where I firmly trod . . .

Tennyson understates the case. Nature exhibitsan amazing, a sinister prodigality of increase and of destruction. A single flesh.fly, Wallace informs us, produces 20,000 larvae, which reach their full size in five days, so that each parent fly may be increased ten-thousand-fold in a fortnight. A pair of our common birds-thrush, blackbird, sparrow, titmouse -if allowed to live and breed unmolested, would have in ten years no less than twenty millions of descendants. The machinery of destruction is, however, in a state of nature, not less efficient than the machinery of growth and increase. It is a somewhat melancholy reflection that a similar law is at work amongst mankind. We may recognize this law without proposing to acquiesce in it. In this instance, as in others, we shall find that civilization and natural selection run counter to each other. As civilization advances the birth-rate falls. This is, apparently, a universal law, complicated though it may be by local conditions or national habits. The birth-rate is steadily falling amongst our own nation and even more decidedly in France and America. In the former the fall has been sufficient practically to arrest the natural increase of population. A phenomenon of this kind, apparently world-wide in its operation and one that could not have been anticipated, must depend upon evolutionary law. Herbert Spencer is inclined to think that intellectual de. velopment and the reproductive faculty have to a certain extent an invert ratio to each other, and that the rapid increase of the population of the world-"even slowbreeding man," Darwin tells us, "has doubled in twentyfive years"- will be arrested as civilization develops. I cannot detain you with any of the ethical problems which such a view suggests. I must content myself with pointing out how evolution seems to be operating, how profound is its influence, and how mistaken we shall probably be if we attribute such large facts as a falling birth-rate solely to temporary and wholly preventable causes.

The relation of the medical profession to the question of the propagation and preservation of the unfit raises many difficult questions, which cannot be adequately con. sidered on this occasion. The question of our responsi. bility to those who shall come after us, though not a new ethical problem-it is found in Plato-has become a practical question only in modern times. It is a principle with which we have henceforth to reckon. The art of medicine was for thousands of years concerned solely with the cure 
or relief of disease. At the present day the prevention of disease bulks hardly less largely in our thought, and this point of view indicates a distinct advance. In the future one may predict with confidence that the preservation of the purity of the race will be regarded as one of the essential tasks of the art of medicine. The whole ques tion, it is almost needless to say, is involved in the greatest difficulty, but it will certainly force itself increasingly upon our attention. It will do so with the greater insistence if we realize that the future physical well-being of the race will be determined more by natural selection than by attention to environment, important though this latter factor may be. That the medical profession.will ever in this country be invested with disciplinary powers for the regulation of marriage seems doubtful. Such control would probably be foreign to the habits of mind of the British race, but we see that attempts have been made in this direction in some of the States of the American Union, and to a lesser extent in Germany, with what degree of success I am unable to say. It seems probable that in this country we shall have to rely upon the operation of an enlightened public opinion-enlightened as it must be, to a large extent, by the influence of the medical profession.

Is the human form destined to undergo important changes in the future under the operation of evolutionary law? Are we to look for the coming of the Super-Man, a conception with which the thought of Nietzsche has rendered us familiar? "What with man is the ape?" says Zarathustra, "a joke or a sore shame. Man shall be the same for Beyond-man, a joke or a sore shame." This is by no means certain. Weismann thinks it doubtful whether man may not have achieved the summit of his development both as regards physique and intellect, and is inclined to look for progress solely in the ethical sphere. Yet some of the facts adduced in this address seem to point decisively to the conclusion that the human body is destined in the course of many generations to undergo at least minor changes. The teeth, the hairy covering of portions of the body, the toes, the special senses, are almost certain to undergo modification. Nor can we limit the proba. bility of change to such parts as these. All we can say in this connexion is that the changes which will come will be the outcome of evolutionary law. Useless organs will be eliminated. Useful organs will undergo progressive adaptation to altered conditions, such as diet, climate, habit, occupation. The possibility of Reversion and of Degeneration will always need to be reckoned with.

A general survey of the relation of Darwinism to the science and art of medicine is likely, I think, in many ways to be salutary. It will certainly tend to breadth of view, to a philosophic appraisement of the factors with which we have to deal, to a recognition of the great under. lying laws and secular processes which are related to our art. It may, perhaps, act as a damper upon enthusiasm when we realize that evolutionary change is slow and only partially under our control ; but, if this be the truth, it is better for us to know and recognize it. Medicine will gain in stability and in influence, as well as in dignity, by being in close relation with the higher thought of the day. It may in some not unimportant particulars react upon that thought. Disease becomes something more than a disagreeable and embarrassing fact when we realize how closely it is related to evolutionary processes, how vivid is the light it is capable of throwing upon evolutionary law. It even takes its place-a temporary place we may hopein the eternal order. "Harmonious order," says Huxley, "governing eternally continuous progress; the web and woof of matter and force interweaving by slow degrees, without a broken thread, the veil which lies between us and the infinite-that universe which alone we know or can know-such is the picture which science draws of the world."

THE third International Congress of Physiotherapy will be held in Paris, March 29th to April 2nd, 1910, under the presidency of Professor Landouzy, Dean of the Paris Medical Faculty. The congress is under the patronage of M. Fallières, President of the French Republic. The work of the congress will be distributed among seven sections : Kinesitherapy, hydrotherapy and thermotherapy, climatotherapy, electrotherapy, treatment by $x$ rays, radium, and light, watering-place treatment, and dietetics. An exhibition will be held in connexion with the congress.

\section{THE IDENTITY OF BRITISH ULCERATIVE COLITIS AND TROPICAL BACILLARY DYSENTERY.}

BY HERBERT P. HAWKINS, M.D., F.R.C.P., PHYSICIAN TO ST. THOMAS'S HOSPITAL.

IN a paper read before the Bristol Medico-Chirurgical Society, 1 on the Natural History of British Ulcerative Colitis, I gave it as my belief that this disease, both the epidemic disease in asylums and the sporadic disease in the open, is a relic of the dysentery which in the seven. teenth and eighteenth centuries covered the whole of Europe. I endeavoured also to ascertain how far we are justified in considering that the British disease is bacteriologically related to tropical bacillary dysentery of the Shiga-Kruse or Flexner type. The evidence as regards the ulcerative colitis of asylums is almost conclusive of the identity of the British and the tropical disease. But as regards the sporadic disease, the evidence would not bear a conclusion. Only in one certain case (Lieutenant Marshall, R.A.M.C.) has Flexner's bacillus been found. My own cases only furnished two instances in which the serum agglutinated Shiga's bacillus, and in no case was the specific dysenteric organism found.

I should like, therefore, to add a note of a sporadic case which, bacteriologically and clinically, was identical with the tropical disease as it occurs in the Philippines and West Indies This case also illustrates a point which the series of cases from St. Thomas's Hospital makes clear, namely, that the grave condition, which is most familiar to us as ulcerative colitis, in which the ulceration of the colon is so deep and extensive that repair is unlikely or impossible, is often preceded by one or more minor attacks, which have considerable natural tendency to subside. I believe that these minor preliminary attacks are not commonly recognized, but are lumped together with other forms of acute diarrhoea. It is in these minor attacks, before other bacteria come into force, that the use of the serum prepared by the Lister Institute is most likely to be of use. It is probable that these attacks are true tropical dysentery of a mild type. In cases of long standing ulceration, such as are commonly seen in hospitals, the specific bacillus may never be fotund, and it is not unlikely that its place has been taken by Bacillus pyocyaneus or by organisms of the coli, paratyphoid, or pyogenic groups.

\section{History.}

A man, aged 48, a metal worker, had in 1905 a severe attack of diarrhoea with griping pain, but he could not remember any other details. In 1907 he had a second attack, lasting two or three weeks, in which he passed blood and mucus, and in 1908 a similar attack of shorter duration. All three attacks occurred in July or August, the season of flies. He had not been out of Englend.

On July 12th, 1909, he was again seized with diarrhoea, and severe griping pain, chiefly in the left flank and groin (lower segment infection). He described the stools, of which there segment infection). He described the stools, of which there were four or five a day, as being "slimy" at first, but on the second day he passed red blood. There was wo tenesmus. For was admitted into St. Thomas's Hospital, presenting diarrhoes such as he had described, the stools being liquid, dark, offensive, with mucus and a little red blood, slight pyrexia, and tenderness over the colon on the left side. At first he experienced considerable griping pain and true tenesmus was present. The rectum was hyperaemic and showed patches of blood-stained rectum was hyperaemic and showed patches of blood-stained serum, with calomel and opium. Improvement was rapid and he left hospital apparently well after a stay of seven weeks.

Bacteriological Report.

Dr. Dudgeon kindly examined a high rectal scraping, with the following result:

"Plate caltivations were made by the direct method on MacConkey's bile salt neutral red lactose agar. A bacillus was obtained which, when tested in various media, gave the cultural characters of the bacillus of Flexner, with the exception that the organism did not form indol. The patient's serum gave a well-marked agglutination reaction with this bacillus with a dilution of 1 in 20 , a good reaction with a dilution of 1 in 50 , and a slight reaction with a dilution of 1 in 100 , within half an hour at room temperature with the microscopical method. It also agglutinnted with an antidysenteric serum (Shiga) with dilutions of 1 in 20,1 in 50 , and 1 in 100 . A rabbit was immanized with the bacillus isolated from the patient. The rabbit's serum, when mixed in suitable dilutions with the 